\title{
The Efficiency of Innovative Marketing Information System: An Empirical Study of Tourism Industry of Pakistan
}

Muhammad Imran Hanif ${ }^{*}$, Shao Yunfei', BAI Xiu-Yin², Hanif Muhammad Shahzad ${ }^{3}$ and Muhammad Tariq Shareef

${ }^{1}$ School of Management and Economics, University of Electronic Science and Technology, Chengdu, 610054, P.R. China

${ }^{2}$ College of Humanities and Law, Chengdu University of Technology, Chengdu, 610059, China

${ }^{3}$ Manager Network Operations-PTCL-Etisalat Pakistan

${ }^{4}$ Islamia University Bahwalpur-Pakistan

\section{Research Objective}

To study the Innovative MKIS efficiency of Tourism Industry in Pakistan and to measure the efficiency and efficiency of Marketing Information System.

\begin{abstract}
An empirical study is conducted to explore the Innovative Marketing Information System in Tourism industry of Pakistan. The study is very beneficial for Hotels, fast food restaurants, tourist resorts, picnic spots and other areas of the sector to measure to what extent Innovative MKIS is efficient and effective. How much Innovative MKIS is contributing to the increase profitability and market value of tourism and can enhance performance of this sector by Innovative MKIS in Pakistan. The study was conducted to identify the importance of procedural improvements of Innovative MKIS and to support the marketing staff. Furthermore, it will add value for customers with product knowledge and help the business organizations to customers preferences and market response. IT based Innovative MKIS efficiency is measured on bases of four models proposed as organizational efficiency proportions by Gounaris, Panigyrakis and Chatzipanagiotou.
\end{abstract}

Keywords: Innovative MKIS; Tourism; Hotels; Restaurants; Fast food restaurants; Market research system; Knowledge sharing; Innovation management; Market

\section{Introduction}

Tourism industry plays vital role in development of an economy. Pakistan is blessed with diverse cultures, landscapes and all weathers of the world. Beautiful mountains, glaciers, lakes, grazing fields and zoos are precious assets of Pakistan. Here, beauty ranges from history of civilization such as Taxila, Harapa and Mohenjo Daro to Himalayan hill stations. This country has numerous mountain peaks over $7000 \mathrm{~m}$, these mountains have a lot of attraction for tourists and adventurers, especially Karakorum 2 (Second highest Mountain in the world). The northern area of the country has several ancient architecture, old fortresses. Chitral and Hunza valleys have magnetic touch towards visitors. The Culture of Pakistan has enormous capital like Badshahi Mosque, Tomb of Jahangir, Shalimar Garden as examples of Mughal architecture. Pakistan was visited by more than 500,000 before the Global economic crisis annually. Tourism marketing is traditionally oriented towards promotion function. But growing demands and recognition of Tourism industry and its marketing requires a more holistic approach to destination management has addresses the purpose of marketing corporations to focus on targeting the Innovative MKIS competitiveness so that the probability of success can be increased on a consistent basis. It pertinent to mention that the need of destiny and importance of stakeholders to take apart in more strategic oriented perspective in proper execution, planning and implementation for the development of tourism.

The importance of efficient and effective marketing information system in tourism industry of Pakistan, is the main concern of this paper. In order to achieve the sharing of information, access of leading resorts, fast food hotels and restaurants in the major cities of Pakistan, how to market, how to increase efficiency of sales, promotion and advertising teams can be improved and the whole mechanism how can be digitalized. To get the intellectual proportions of destination management on real ground to be searched out efficiently, the researchers, is targeted the importance to support the complete marketing process by enhancing refined destination of Innovative MKIS.

Besides all these natural resources and blessed assets, it is immense need to highlight and critically and empirically evaluate the performance of Innovation MKIS in tourism Industry of Pakistan. There is an enormous need to study the current Innovative MKIS of leading hotels, resorts, fast food chains and five star hotels and how Innovative MKIS is facilitating the customers via online access and meeting the orders and requirements of the present industry. How it is further be improved and adding value to the productivity of the employers and developing image in terms of creating new market.

\section{Literature Review}

Philips Kotler defines Innovative MKIS “A marketing information system is an interacting and long-lasting structure of people, actions and tools to sort, sort, evaluate, and distribute pertinent, accurately and timely information for use by marketing decision making to improve their marketing planning, execution, and control". Cox and Good [1] gave primary definition of Innovative MKIS Cox and Good [1], who

*Corresponding author: Dr. Muhammad Imran Hanif, PhD Scholar, Schoo of Management and Economics, University of Electronic Science and Technology, Chengdu, 610054, P.R. China, Tel: +86-15928714565; E-mail: mimranhanif1@gmail.com

Received December 09, 2013; Accepted January 21, 2014; Published January 28, 2014

Citation: Hanif MI, Yunfei S, Xiu-Yin B, Shahzad HM, Shareef MT (2014) The Efficiency of Innovative Marketing Information System: An Empirical Study of Tourism Industry of Pakistan. Int J Econ Manag Sci 3: 175. doi: 10.4172/2162-6359.1000175

Copyright: ( 2014 Hanif MI, et al. This is an open-access article distributed under the terms of the Creative Commons Attribution License, which permits unrestricted use, distribution, and reproduction in any medium, provided the original author and source are credited. 
described Innovative MKIS as a set of methods and procedures for effective planning, execution and demonstrating information needed in taking marketing-related decisions.

Noori and Hossein projected a new decision-support-system (DSS) is a framework of marketing in the B-2-B (business-to-business) arena based on customer-relationship management (CRM) and knowledgedriven marketing decision support system to help related-field graduate students and marketing managers. The work of fiction involvement of their work lies in integrating and coordinating marketing CRM and DSSs with reference to knowledge-driven marketing in B2B promotion, in both tentative and pragmatic aspects. Civilizing MDSSs with CBR was planned expectations area along with scheming and budding DGSS for marketing system.

Michael J. Valos and David investigated the pressure of Porter's strategy types on the use of customer relationship management (CRM) techniques and established market research. Does strategy and plans explain differences in the use by organizations of marketing research and CRM? However, four roles of customary market research: enhancing strategic decision making, increasing usability of obtainable data, presenting plans to senior management, and achieving efficiency, production and political outcomes.

Hanif and Shao [2], answered the questions that how we can produce diverse workforce in shape of fresh graduates available for recruitment. They also highlighted that how HR of leading public and private organizations can recruit diversified potential, competitive personality characters and traits within a culture it was articulated that the role of imminent teams in integrating and coordinating miscellaneous Marketing Information System techniques, explored and addressed the feasibility of preparation and executing the incorporation of four often independent marketing information management techniques and procedures, i.e. bloodthirsty intelligence (CI), customer relationship management (CRM) and Corporate Social Responsibility, market research $(\mathrm{MR})$. data mining $(\mathrm{DM})$ and market and CI potential - a wide range of calculated analytic competencies listening carefully on psychotherapy of the exterior business atmosphere through secondary research at a worldwide, national, manufacturing and human being enterprise.

The research and investigation was conducted to see the sights that most of the applications of marketing information systems (Innovative MKIS) come into view to prop up marketing schedule function rather than marketing strategic function. Xianzhong intentional the calculated compass reading of marketing information systems. The study examines the current practices, weaknesses and meeting point of the deliberate occupation of marketing, and the submission of information systems in at the bottom of the strategic function. A further step was planned to continue this research was to make bigger the study into other industries. A comparison of the findings based on different industries could highlight the common strategic functions of Innovative MKIS and the unique function associated with industry differences

How widely a firm explores knowledge and innovation? Importance for innovation processes in small and medium-sized enterprises (SMEs) are broadening, where knowledge and other resources are often limited. Hence, it is no surprise that the number of SMEs pursuing innovation routes is growing despite organizational challenges that may arise from dealing with various external partners. The research on the differences between innovative and non-innovative small businesses has suggested that differences in innovativeness stem mainly from the organizational characteristics of the companies rather than the external circumstances (e.g., McAdam, McConvery \& Armstrong, Forsman \& Rantanen).

Hanif and Shao [3] said that impact of talent management strategies has remarkable effects on human resource perceived outcomes especially on output, efficiency and productivity of organization and employees

The major condemnation heading for existing DMISs is that they are inconvenient and do not imitate the right picture and research requirements of the industry as a whole. This can be accredited to a certain extent to the fact that most are sponsored, premeditated and urbanized by government tourism departments with minor straight involvement by industry operators.

\section{Theoretical Framework}

The primary classification of Innovative MKIS was accessible by Cox and Good [1], who explained them in shape of measures, procedures and strategies for preparation and demonstrating information essential for enchanting the marketing decisions support system. despite the fact that the submission of in sequence know-how in marketing decision making in 1960s, it was throughout in 1990s that detailed applications were functional to definite marketing tasks: for graphic, marketing case-base reckoning systems and procedures [4], connoisseur systems of marketing researched by Sisodia, and management support systems for marketing and decision making systems. The principle of the most basic such systems and procedures were to get together, analyzed, appraise, put in order and dole out timely, applicable and precise in sequence for marketing decision makers. Even though particularly linking to marketing decisions, they go halves their basic main beliefs with other IT - information support system.

The execution of Innovative MKIS has a variety of cost for the corporation. Raymond and, the calculating of recognized marketing campaign and procedures were studied in detail. Many researchers have worked and discussed the impacts of Innovative MKIS [5], in the method to enhance the extend of the corporation is market sloping. In addition, in the direction of market orientated research tributary, therefore, many other convincing methods to give details how the utilize Innovative MKIS, improves the company's capability to line up its conclusion in accordance with the circumstances of its market $[6,7]$ and on decision making in different papers [8] to become more effectual in formative customer's needs and preferences and orientation, worked by Sisodia.

\section{Conceptual Model}

Lastly, it's really sound confirmation to bear a noteworthy association sandwiched among the acceptance of Innovative MKIS systems and the organization's productivity [7] they help to diminish equipped price by mounting efficiency and the efficiency of human resources and line managers utilize their time productively. The key requirement for getting these advantages is to set up an effectual system. Despite this unremitting progression of Innovative MKIS, there is no undisputed description of their success has yet been neither agreed, nor it is a relevant measure of it (Figure 1).

\section{Internal magnitude of Innovative MKIS efficiency}

If we talk about the advantages from Innovative Marketing information system and Marketing Intelligence System, the organizations avails are too much. The initial advantage, a company derives by utilization of effective and efficient Information Technology based Innovative MKIS is the improvements in the treatment and 


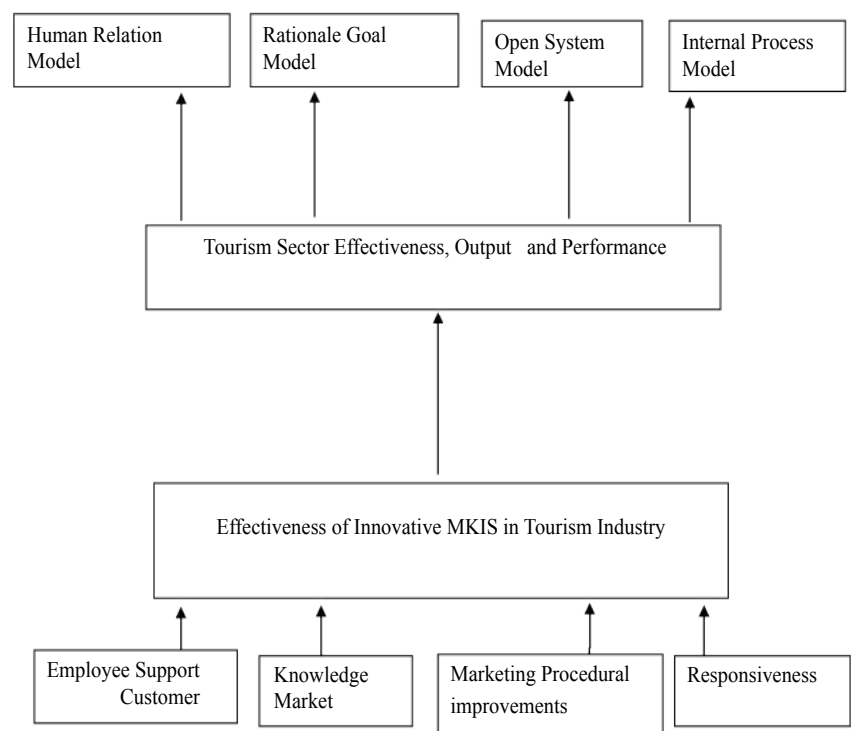

Figure 1: A Hypothetical- Conceptual Model

reporting system of such organization and enhances the exposure. Information dispensation becomes too fast and the top managements of the company become able to correlate applicable information from other reliable sources outside and inside the organization, this data is nearly impossible to accumulate and use then in a significantly and incorporated fashion, without the essential IT communications. The basic principles of Innovative MKIS applications are to put together data and feed inputs from a variety of managerial functions into a holistic and significant map of the company's actions and operations, depicting its exchanges with suppliers, patrons, and customers. As a consequence of practicing it in an opportune manner, pronouncement making is improved by depending the facts than hunch and perception.

Investigation for the collision marketing efforts that Innovative MKIS have on an organization's talent is predominantly enlightening, in such admiration. Adopting IT-based Marketing Information System can facilitate to get better interior and exterior communication between social group, co-workers of different departments of organization and especially in the marketing and sales department and other efficient units alike, because communication has become easier, integral, cheap, volatile and faster, plummeting the capacity for conflict between workers and managers. It gives justification for decision making in more purpose information and information that the system generates and facilities the customers and organization. This is a chief precondition for mounting sensible and triumphant marketing plans, resultantly, it influences both the company's marketing planning and execution process and the product of this procedure [9].

\section{External magnitude of Innovative MKIS efficiency}

The subsequent significant advantage of Information Technology based Marketing Information Systems, is aptitude to watch a company's market surroundings additional efficiently, purposely with high opinion to client affairs focusing the customers as top most importance, and therefore to lend a hand managers in gathering the marketing and selling objectives and priority.

In this fashion, the organization enhances the requirements and wishes of the customers in focus [7], as results it permits the organization to react more efficiently to their prospects. This is because, a clear advertising and promotional techniques, strategy and the compulsory intelligence support system based on IT allows it not only to watch business dealings but, more prominently, to appreciate the human being behind the business deal as customer [10]. furthermore, decoding consumer buying behavior and decision making function permits and responds the company not only to recognize customers' current requirements except also to predict their future requirements more obviously. This results in translating to senior customers' happiness, pleasure and fulfillment of expectations and, from side to side that, to enhance and improve in market-share.

Dependency of relationships between the external and internal magnitude and proportions of Marketing information systems of any organization, its efficiency while bearing in mind the concept of managerial efficiency, Quinn put forward four main factors: constancy and employee centricity and internal process proportions, and flexibility (elasticity) and moldiness, organizational competence involves open system proportions. The regular values, norms and beliefs of the organization, condition its priorities, and resolve which one of the four reasons and reasons and aspects will be established, one in judging the extent of usefulness, seeing as it is complicated for any organization to at the same time do extremely well under all four headings.

Alternatively, in a study [11] elaborates that the predictable zero correlation among the open systems and the internal process magnitude of efficiency does not essentially apply all together in situations. For case in point, under circumstances of confused, fundamental change the company's administration becomes practical in respond to expected changes in the surroundings.

The studies has examined in the part "interior proportions of Innovative MKIS efficiency" construct it obvious that systems have the latent to pressure a lot of marketing-related proportions and scopes of the company's inner operations, connotation that the efficiency of the system is a task of its definite aptitude to give way the probable payback recognized. On the above basis, the subsequent research intention is elevated for examination

Two key proportions of Innovative MKIS efficiency are valid to the system's collision on practical improvements and the prop up of marketing staff: The External proportions of Innovative MKIS efficiency" identifies a next imperative feature of Innovative MKIS efficiency: the degree to of system, contributes to the expansion of the company's exterior operations. Therefore, a subsequent investigate proposal is highly developed for examination.

Two key proportions of Innovative MKIS efficiency are appropriate to the system's collision on the accomplishment of improved customer knowledge and market receptiveness: The journalism reviewed "Interrelationships between interior and exterior proportions of Innovative MKIS efficiency" elaborates that organization have to uphold control over compulsory organizational re-engineering in reply to the recent developments complementary execution of the Innovative MKIS while concomitantly promotion the organizational sincerity, openness and decentralized choice making that give confidence staff to take initiatives.

The internal and external proportions of Innovative MKIS have positive impact on managerial efficiency: Eventually, the sub-section of the appraisal connecting to simultaneous strength proposes that an effectual Innovative MKIS have an impact on all four variables of managerial efficiency. Hence, any compute for assessing the efficiency 
of an Innovative MKIS should be clever to give details an important quantity of difference in managerial efficiency. As a result, an ultimate investigate proposition is advanced for examination.

Innovative MKIS efficiency has an important impact on organizational efficiency: In commerce with this complexity, the bulk of scholastic studies stay behind imperfect in treating the impact of any system on productivity, market share and sale, as alternate actions of efficiency [12]. Evidently, there is advantage in bearing in mind monetary indicators, substantiation of efficiency, but conceptualizing the idea of system efficacy also requires deliberation of the nonmonetory aspects.

This prospect that organizations lay emphasis on various efficiency methodology and criteria has also established experiential support in the work of Buenger et al. [13]. As a consequence, a contradiction that arises regarding the coexistence of steadiness and sequence (internal process values), seeing as coping with such situation frequently calls for organizations that are at the same time unwavering and energetic.

\section{Methodology}

The sample population targeted was the service industry of Pakistan. The sample data was collected from brand managers, assistant managers and Marketing Managers, normally serving in middle level management of each organization of hotel industry of Pakistan. The hotel industry hotels, restaurants, fast food chains, and resorts. We selected the organizations that have an IT/MIS department and use computer based information systems for conducting their business operations. Potential respondents will be selected from Telephone Directory from Hotel Industry, fast food chain i.e. KFC, Pizzahut, MacDonalds, resorts and restaurants from Islamabad, Lahore, Karachi and Northern areas and a questionnaire will be floated through mail and direct visit to get the desired information. Sample size will be 250 .

After the assenting responses, three hundred questionnaires were targeted to send to targeted population and customers of Hotel industry. A covering letter briefing the study and its objective was enclosed with each pair of questionnaire. Circulating one hundred questionnaires in Islamabad and Rawalpindi Market, the response rate was very slow and employees even don't know about the importance of Innovative MKIS and its effectiveness. We received only 43 questionnaires out of 100 from federal capital and Rawalpindi, the response rate was almost $40 \%$, then, the author gave follow up calls to each service firm who did not return the filled questionnaires.

\section{Discussion, Data Collection and Results}

Therefore, the deposit of this paper presents the results of strengthening literature review and then to find out and observe the usability of Marketing information system implementation and efficiency and explains the research propositions which drive the study. Hotel industry has selected as target market of Pakistan. The methodology of current study is exploring the Marketing information systems and decision supports systems efficiency is judged critically and explored in leading fast food chains and five stars hotels in Islamabad. The research data are analyzed, and the conclusion presented.

For data collection, the instrument was adopted, Exploratory and confirmatory factor analysis were implemented to show that the projected measuring Instrument is acceptable method of reliability and validity. All the items are measured on a 5-point likert scale. The efficiency of Innovative MKIS is establish to encompass both internal and external components, connected on one part to the degree to which the user organization improves functional efficiency and commercial climate and on the other to its acceptability and adaptability to market circumstances and its customer responsiveness. The gadget is capable of integrating these into a holistic measure. It is not necessary that an instrument reliable and valid in a situation is also reliable and valid in any other environment. That's why the pair of questionnaire was initially reviewed by the six experts and academicians. To improve the face validity and discriminant validity an item sorting exercise was also conducted by the nine experts. A pilot test was also conducted initially by getting data from ten respondents.

Besides face validity, each variable was also tested for reliability with Cronbach's alpha. To check the construct validity of all dimensions against each construct, the authors applied confirmatory factor analysis. Confirmatory factor analysis confirms whether each item (of a variable) correlates with its factor.

The statistical results shown in Figure 2 and Tables 1-3 depict the nature and strength of relationships among the variables. Path analysis conducted in AMOS ver. 17.0 tests the first order relationships between environmental forces and the realized strategies, and further checks the second order relationship between fitness of the strategies and business performance. We also compare the results of impact of business strategy with impact of IS strategic alignment on performance.

After the assenting responses, three hundred questionnaires were targeted to send to targeted population and customers of Hotel industry. A covering letter briefing the study and its objective was enclosed with each pair of questionnaire. Circulating one hundred questionnaires in Islamabad and Rawalpindi Market, the response rate was very slow and employees even don't know about the importance of Innovative MKIS and its effectiveness. We received only 43 questionnaires out of 100 from federal capital and Rawalpindi, the response rate was almost $40 \%$, then, the author gave follow up calls to each service firm who did not return the filled questionnaires.

Recognizing the importance of Innovative MKIS, this momentous gap and rationale in the literature, the work was investigated to find out the information and to revise set out by contributing towards its declaration by investigative and empirically validating an instrument is used to capture the concept of efficiency in Innovative MKIS. In primary stage, it has been reviewed thoroughly in light of the existing literature. Later on, enthused on the expansion of a gadget that was functional and tested empirically in the hotel industry. The instrument is adopted from the study of four models proposed as organizational efficiency proportions by Gounaris, Panigyrakis and Chatzipanagiotou.

The statistics obtainable and analyze here based on the study of five-star hotels in Pakistan, fast food chains, rest houses and restaurants

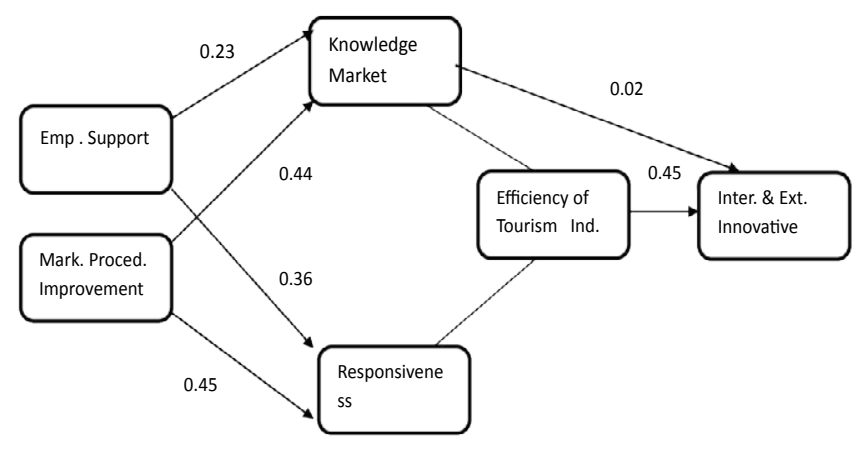

Figure 2: Standardized Regression Weights 
Citation: Hanif MI, Yunfei S, Xiu-Yin B, Shahzad HM, Shareef MT (2014) The Efficiency of Innovative Marketing Information System: An Empirical Study of Tourism Industry of Pakistan. Int J Econ Manag Sci 3: 175. doi: 10.4172/2162-6359.1000175

Page 5 of 6

\begin{tabular}{|c|c|c|c|}
\hline \multicolumn{2}{|c|}{ Items (as included in the questionnaire) Scales The Innovative MkIS helps us to ... } & \multirow{2}{*}{$\begin{array}{c}\text { Mean } \\
5.87\end{array}$} & \multirow{2}{*}{$\begin{array}{c}\text { Std. deviation } \\
1.28\end{array}$} \\
\hline \multirow{4}{*}{$\begin{array}{l}\text { Marketing procedural } \\
\text { improvement }\end{array}$} & Improve control of marketing programs & & \\
\hline & Improve marketing plan activities & 5.61 & 1.07 \\
\hline & Create efficient marketing reporting & 5.98 & 0.76 \\
\hline & Improve decision making & 5.85 & 0.91 \\
\hline \multirow{3}{*}{ Employees support } & Develop efficient marketing activities (time saving and lower level of routine work) & 5.83 & 0.88 \\
\hline & Develop better services to the customer & 5.97 & 1.47 \\
\hline & Get better feedback of the market & 5.03 & 0.96 \\
\hline \multirow{4}{*}{ Customer knowledge } & Improve our customer's satisfaction & 5.65 & 1.05 \\
\hline & Increase our sales volume & 5.86 & 0.97 \\
\hline & Improve communication between the marketing department personnel & 5.6 & 1.1 \\
\hline & Reduce cost of marketing program & 5.92 & 1.21 \\
\hline \multirow{4}{*}{ Market responsiveness } & Acquire valuable knowledge of our customers' needs & 5.54 & 1.57 \\
\hline & Launch more quickly new services in the market & 5.13 & 1.81 \\
\hline & Increase sales promotion activities & 5.2 & 1.94 \\
\hline & Improve our marketing research (i.e. online surveys) & 4.84 & 1.91 \\
\hline
\end{tabular}

Table 1: The objective of the analysis was to select a set of questions that could be used toassess the performance of an Innovative MKIS with respect to the identified effectiveness.

\begin{tabular}{|c|c|c|c|}
\hline Items & Mean & Std. deviation & $\begin{array}{l}\text { Cronbach's a } \\
\text { coefficient }\end{array}$ \\
\hline \multicolumn{4}{|l|}{ Internal process model } \\
\hline My co-workers provide me with good, usable information & 5.51 & 1.169 & \multirow{4}{*}{0.921} \\
\hline Information given me by others staff members is usually very helpful in my work & 5.46 & 1.227 & \\
\hline It is easy to give a precise explanation of the goals of our organization & 5.52 & 0.804 & \\
\hline Members of our organization have a clear understanding of its goals & 5.59 & 1.062 & \\
\hline \multicolumn{4}{|l|}{ Human relations model } \\
\hline Our work efforts during the date are well organized & 5.37 & 0.988 & \multirow{8}{*}{0.825} \\
\hline There is a feeling of staff cohesion and team work & 5.66 & 1.152 & \\
\hline Employees trust each other & 5.41 & 1.141 & \\
\hline There is an atmosphere of friendship at work & 5.19 & 0.98 & \\
\hline There is a feeling of staff cohesion and team work & 5.18 & 1.873 & \\
\hline Employees possess skills adequate to their assignments & 4.52 & 1.619 & \\
\hline Members of the staff are well qualified for their jobs & 5.13 & 1.288 & \\
\hline Staff members have the capacity to do their work & 5.68 & 1.036 & \\
\hline \multicolumn{4}{|l|}{ Open system model } \\
\hline The size of our office is steadily increasing & 5.12 & 1.771 & \multirow{7}{*}{0.944} \\
\hline Each year we have a large staff than the year before & 4.48 & 1.817 & \\
\hline We have improved our customer satisfaction & 5.45 & 1.989 & \\
\hline In a crisis we are usually able to get our work done & 5.71 & 1.006 & \\
\hline We are flexible enough to take on new tasks & 5.67 & 1.49 & \\
\hline Our responses to emergencies are usually adequate & 5.43 & 1.223 & \\
\hline We adapt well to new demands on our organization & 5.79 & 1.431 & \\
\hline \multicolumn{4}{|l|}{ Rational goal model } \\
\hline The organization makes a better use for its resources & 5.74 & 0.917 & \multirow{7}{*}{0.964} \\
\hline This organization is highly productive & 5.68 & 1.667 & \\
\hline The volume of work accomplished is quite large & 5.43 & 1.219 & \\
\hline The work done in the organization is high caliber & 5.42 & 0.974 & \\
\hline We have acquired competitive advantage & 6.05 & 1.108 & \\
\hline We have improved our position in the market & 5.04 & 1.794 & \\
\hline We have decreased our costs & 5.51 & 1.845 & \\
\hline
\end{tabular}

Table 2: Respondents Profile, Source: descriptive statistics and reliability coefficient, adapted from Rohrbaugh (1981).

in the vicinity of Islamabad and Rawalpindi. investigating the adoption and use of IT-based Innovative MKIS by the organizations serving in hotel industry of Pakistan. Fast food chains, resorts, i.e. Pizahut, MacDonalds, KFC, renowned hotel chains, rest houses and guest houses were selected to investigate. The sample framework has excluded smaller hotels and restaurants from the lower star categories, even they represent the prevalence of the industry. Confirmatory factor analysis (CFA) was applied on the questionnaire to purify and testing of instrument that is adopted earlier in other research journals. Desk research was held before designing the study and found that these hotels made insignificant use of Innovative MKIS, mainly at the operational level such as billing modules and accounting information systems. It was observed that real investigation based on successful marketing information system is lacked and even the management is reluctant to share their privacy of information and customers.

Recognizing the importance of Innovative MKIS, this momentous 
Citation: Hanif MI, Yunfei S, Xiu-Yin B, Shahzad HM, Shareef MT (2014) The Efficiency of Innovative Marketing Information System: An Empirical Study of Tourism Industry of Pakistan. Int J Econ Manag Sci 3: 175. doi: 10.4172/2162-6359.1000175

Page 6 of 6

\begin{tabular}{|c|c|c|}
\hline Frequency $(117 * 2=234)$ & $\mathbf{N}$ & \%age \\
\hline \multicolumn{3}{|l|}{ Gender } \\
\hline Male & 168 & $72 \%$ \\
\hline Female & 66 & $28 \%$ \\
\hline \multicolumn{3}{|l|}{ Age } \\
\hline $25-34$ & 35 & $15 \%$ \\
\hline $35-44$ & 112 & $48 \%$ \\
\hline 45-54 & 78 & $33 \%$ \\
\hline 55 and above & 9 & $4 \%$ \\
\hline \multicolumn{3}{|l|}{ Management } \\
\hline CEOS & 9 & $4 \%$ \\
\hline GM/MD/ Managers & 108 & $46 \%$ \\
\hline $\begin{array}{l}\text { Brand Managers, AMs, IT/ IS } \\
\text { Managers }\end{array}$ & 117 & $50 \%$ \\
\hline \multicolumn{3}{|l|}{ Experience } \\
\hline $1-5$ years & 38 & $16 \%$ \\
\hline $6-10$ years & 70 & $30 \%$ \\
\hline $11-15$ years & 77 & $33 \%$ \\
\hline $16-20$ & 40 & $17 \%$ \\
\hline $21 \&$ above & 9 & $4 \%$ \\
\hline \multicolumn{3}{|l|}{ Education } \\
\hline Graduate & 73 & $31 \%$ \\
\hline Post Graduate & 110 & $47 \%$ \\
\hline MS/MPHIL & 30 & $13 \%$ \\
\hline PHD & 21 & $9 \%$ \\
\hline
\end{tabular}

gap and rationale in the literature, the work was investigated to find out the information and to revise set out by contributing towards its declaration by investigative and empirically validating a tool and instrument to capture the notion of efficiency in an Innovative MKIS. As a first step, it thoroughly reviewed the existing literature. It then enthused on to the expansion of a gadget that was functional empirically in the hotel industry.

\section{Conclusions}

The paper concludes with general discussion, and suggests that the idea of information-system efficiency is a make comprising such integral, among numerous other research papers it was given due importance towards the productivity, efficiency, flexibility, control, internal communication and information management for the success and improvement of marketing and customer oriented decision making system.

Furthermore, they uncharacteristically didn't uphold an independent marketing department. The organizations are missing effective marketing channels, campaigns, data gathering tools, as the accountability of the technical personnel, important trainings, hands on experiences, Innovative MKIS compass reading and importance. The findings of this study reflect the practice of a detailed analysis conducted first by CFA and then through AMOS, Tests were applied due to multi regression analysis.

\section{Limitations}

The study has some serious limitations. The scope of research is restricted to only Rawalpindi and Islamabad. It should be further explored to the mega cities i.e. Lahore, Karachi and Peshawar. It seems that the study is lacking detailed discussions seeking importance and realization of the Innovative MKIS cost effective implementation and efficiency. The research is conducted in short time period. It has missing the feed- back from a large number of sample sizes.

\section{Further Research}

Future research may be conducted keeping in view the limitations of the study. Research will produce sound results if, the sample size will be further increased by increasing the scope of the research. Number of metropolitan cities, and northern region of Pakistan and research can be conducted in other developing and under-developed countries of Asia should be explored to get good findings. Innovation and Knowledge sharing in Hotel Industry needs to be explored. Customer point of view is not targeted rather than only the views of brand managers, assistant managers serving the targeted organizations, have been incorporated.

It is recommended for future research that role of HR practices can be checked with knowledge sharing and Innovation. Link of HR practices, Knowledge sharing can also be tested empirically with mediating or moderating role of effective commitment or trust of employees in SMEs and multinational companies in under developing and developing countries like China, India, Pakistan, Malaysia and many other countries.

\section{References}

1. Cox DF, Good RE (1967) How to build a marketing information system, Harvard Business Review 45: 145-54.

2. Hanif, Shao (2011) Talent Hunt of Diverse Workforce can be achieved: By Educating and Implementing Similar and Equitable Education Practices in a Culture, Journal of Education and Practice, 2(1).

3. Hanif, Shao (2013) The role of talent management and HR generic strategies for talent retention 7: 2827-2835.

4. Burke RR, Rangaswamy A, Wind J, Eliashberg J (1990) A knowledge-based system for advertising design. Marketing Science 9: 212-29.

5. Gaskin B (1994) Using DSS to boost sales and marketing, CMA, The Management Accounting Magazine, pp. 13-16.

6. Kitchen PJ, Dawes J (1995) Marketing information systems in smaller building societies, International Journal of Bank Marketing 13: 3-9.

7. Colgate $M(2000)$ Marketing and marketing information system sophistication in retail banking, Service Industries Journal 20: 139-152.

8. Cassie C (1997) Marketing decision support systems. Industrial Management \& Data Systems 97(7/8): 293-297.

9. Amaravadi CS, Samaddar S, Dutta S (1995) Intelligent marketing information systems: computerized intelligence for marketing decision making, Marketing Intelligence \& Planning 13: 4-13.

10. Davenport TH, Harris JG, Kohli AK (2001) How do they know their customers so well?, Sloan Management Review 42: 63-73.

11. Kalliath TJ, Bluedorn AC, Gillespie DF (1999) A confirmatory factor analysis of the competing values instrument, Educational and Psychological Measurement 59: 143-158.

12. Krishnan GV, Sriram RS (2000) An examination of the effect of IT investments on firm value: the case of Y2K-compliance costs, Journal of Information Systems 14: 95-109.

13. Buenger V, Daft RL, Conlon EJ, Austin J (1996) Competing values in organizations: contextual influences and structural consequences, Organization Science 7: $57-576$ 